Research Article

\title{
Experimental Research on Bending Bearing Capability of Grouted Double Mortise-Tenon Joint for Prefabricated Metro Station Structure
}

\author{
Xiuren Yang $\mathbb{D}^{\mathbb{D}},{ }^{1,2}$ Fang Lin $\mathbb{D}^{1,2}$ and Meiqun Huang ${ }^{1,2}$ \\ ${ }^{1}$ Beijing Urban Construction Design and Development Group Co., Ltd, Beijing 100037, China \\ ${ }^{2}$ National Engineering Laboratory for Green \& Safe Construction Technology in Urban Rail Transit, Beijing 100037, China \\ Correspondence should be addressed to Fang Lin; felyo@foxmail.com
}

Received 20 December 2020; Revised 24 February 2021; Accepted 5 March 2021; Published 17 March 2021

Academic Editor: Yunteng Wang

Copyright (c) 2021 Xiuren Yang et al. This is an open access article distributed under the Creative Commons Attribution License, which permits unrestricted use, distribution, and reproduction in any medium, provided the original work is properly cited.

The grouted mortise-tenon joint, invented as the connection between the large prefabricated elements, is the most important component in the prefabricated underground structures. This paper conducts analysis of load-carrying capacity performance and failure mode with $1: 1$ prototype test in key working direction of different double mortise-tenon joint types for the prefabricated metro station. The resistance moment is developed and used to analyze the bending bearing characteristic curve, and the corresponding test results of each stage of the characteristic curve are described in detail. In addition, the bending bearing performance of different types of double-tenon joints under different load conditions is compared. The test results clarify the ultimate failure mode of double-tenon joint and the variable bearing capacity characteristics of the joint with the increase in axial load and explain the bearing performance of each stage. It is also found the auxiliary pretightening device is helpful to delay the appearance of cracks and improve the bearing capacity, especially when it is set on the tension side. The research results have important application value for the joint design of prefabricated metro station structures.

\section{Introduction}

Since the rapid development of urban rail transit in China in 2000, it has maintained a high-speed growth trend. All cities are facing tremendous pressure in terms of construction period, environmental impact, labor shortage, project quality, etc. The traditional open-cut metro station structure is generally constructed by cast-in-place construction technology, which has many construction links, slow construction speed, serious construction dust and noise pollution, a large number of on-site workers and high labor intensity, difficult project quality control, and frequent leakage, and it is greatly affected by the climate conditions.

Prefabricated building structure has significant advantages such as high efficiency, high quality, and green and environmental protection and is widely used in the field of aboveground construction, especially in developed countries such as Europe, America, and Japan, while the application of underground structures is mainly concentrated in shield tunnel engineering. In order to solve the problem of winter construction in the former Soviet Union, the prefabricated technology was studied and applied in the open-cut metro station and shield-driven tunnel structure engineering. Due to the limitations of early technology, the large-scale metro station mostly adopts the prefabricated rectangular frame structure with relatively complex system, and the joints are mainly connected by cast-in-place concrete, so the prefabrication advantage is not obvious [1-10].

The prefabricated station of Changchun Metro Line 2 is a two-story single arch long-span structure with open excavation. The prefabricated station structure is $20.5 \mathrm{~m}$ wide and $17.45 \mathrm{~m}$ high. It is built by assembling seven $2 \mathrm{~m}$-wide prefabricated components without any concrete wet spraying (see Figure 1), which belongs to the fully prefabrication type. Compared with the aboveground structure, shield tunnel, or foreign prefabricated structure with cast-in- 


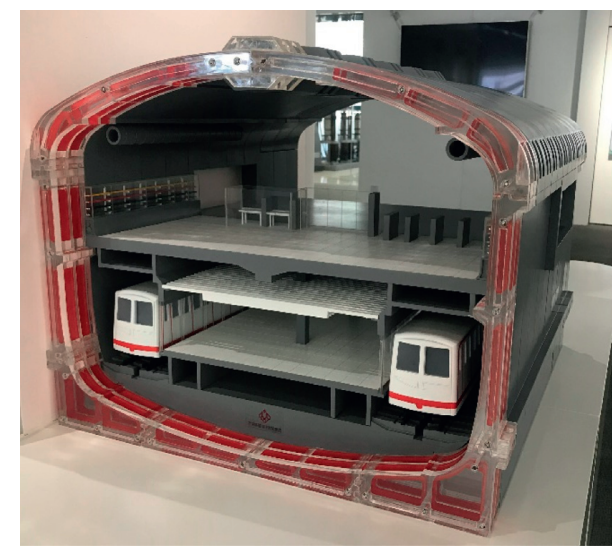

FIGURE 1: Model of prefabricated metro station.

place joint, this prefabricated metro structure has great differences in the use of environmental characteristics, stress characteristics, waterproof requirements, construction technology, and other aspects.

The grouted double mortise-tenon joint is used in most of the connections between prefabricated components for prefabricated stations (see Figure 2). The mechanical behavior of the joint is the key factor affecting the overall mechanical behavior of the prefabricated structure [11-14]. There is no precedent of grouted double mortise-tenon joint used in large underground structure [15-17]. Therefore, in order to study the mechanical behavior of the grouted double mortise-tenon joint under eccentric compression, a set of self-developed joint comprehensive test system was applied to carry out the bearing performance and destructive test of the prototype joint specimen (the key bearing direction is $1: 1$, and the width of noncritical direction is $1 / 2$ ). The bending bearing capacity and failure mode of grouted double-tenon joints with the same type and structure are studied in depth.

\section{Test Scheme}

In this study, ten groups of loading tests were carried out for the double-tenon joint under different axial force and bending moment combinations, including three types of joints: without auxiliary pretightening device, auxiliary pretightening device on tension side, and auxiliary pretightening device on compression side. The specific test conditions are shown in Table 1 [18]. The types and structures of the three test joints are shown in Figure 3. The auxiliary pretightening device (blue-dotted line in Figure 4; specific dimensions are shown in Figure 3) refers to a boss structure on the outside of the joint to install two steel bars which can exert pretension. The test loading mode and loading sequence are shown in Figure 4. In the joint test, the straight joint specimen is applied axial load and bending moment independently. The axial load forms the joint axial force, and the bending moment is formed by applying the transverse concentrated force. This loading mode can combine different axial loads and bending moment values arbitrarily. In the loading sequence, multistage stable axial load is set and loaded from large to small. Under the condition of maintaining a certain axial load, transverse concentrated load is applied step by step from small to large to form bending moment loading from small to large. In order to describe the test phenomenon conveniently, the side with opening tendency is defined as tension side, and the side with compression tendency is defined as compression side. The tenon on tension side is defined as tenon $\mathrm{A}$, and the tenon on compression side is defined as tenon $\mathrm{B}$.

The stable axial load is set at $1250 \mathrm{kN}, 1000 \mathrm{kN}$, and $500 \mathrm{kN}$, and the bending moment increases gradually from $0 \mathrm{kN} \cdot \mathrm{m}$ until the specimen is destroyed. During the test, the development law of crack on the joint surface, joint angle, surface concrete stress, and reinforcement stress change law were observed, and the basic mechanical behavior of joint was analyzed; different types of joints were compared and analyzed.

\section{Analysis of Test Results}

In the test, the crack development is the most direct performance of the joint bending load. Therefore, this paper will start from the crack development law to analyze the bending bearing characteristics.

3.1. Crack Development and Change Law of Joint. Through observation, the double-tenon joint specimens go through the following stages: crack appearance $\longrightarrow$ crack development $\longrightarrow$ crack transfixion of tenon on tension side $\longrightarrow$ crack transfixion between mortises $\mathrm{A}$ and $\mathrm{B} \longrightarrow$ structural crack transfixion $\longrightarrow$ structural instability.

From the test results of various working conditions, the load acting value of structural crack transfixion is basically consistent with that of structural instability, which indicates that the bearing allowance from structural crack transfixion to structural instability is limited. The crack development in various types of double-tenon joints is analyzed as follows.

3.1.1. Crack Development of the Joint without Auxiliary Pretightening Device. Taking $1000 \mathrm{kN}$ axial load condition as an example (see Figure 5), the crack development patterns under various bending moments are shown in Table 2.

The crack development law of joint specimen without auxiliary pretightening device under different axial load conditions is summarized in Figure 6.

(a) Under the condition of small axial load $(500 \mathrm{kN})$, microcrack I first appears at the shoulder position (point $A_{a}$ ) of tenon $\mathrm{A}$, which develops along the root of tenon A to the shoulder of tenon B. At the same time, another crack II with the same starting position (point $A_{a}$ ) appears, which develops along point $A_{b}$ and point $A_{c}$ of tenon $\mathrm{A}$, forming a through-crack of tenon $\mathrm{A}$.

(b) Under the condition of large axial load $(1000 \mathrm{kN}$ and $1250 \mathrm{kN}$ ), the first crack also appears at the shoulder position $A_{a}$ of the tension side. The crack grows along the $A_{b}$ direction and develops along the 


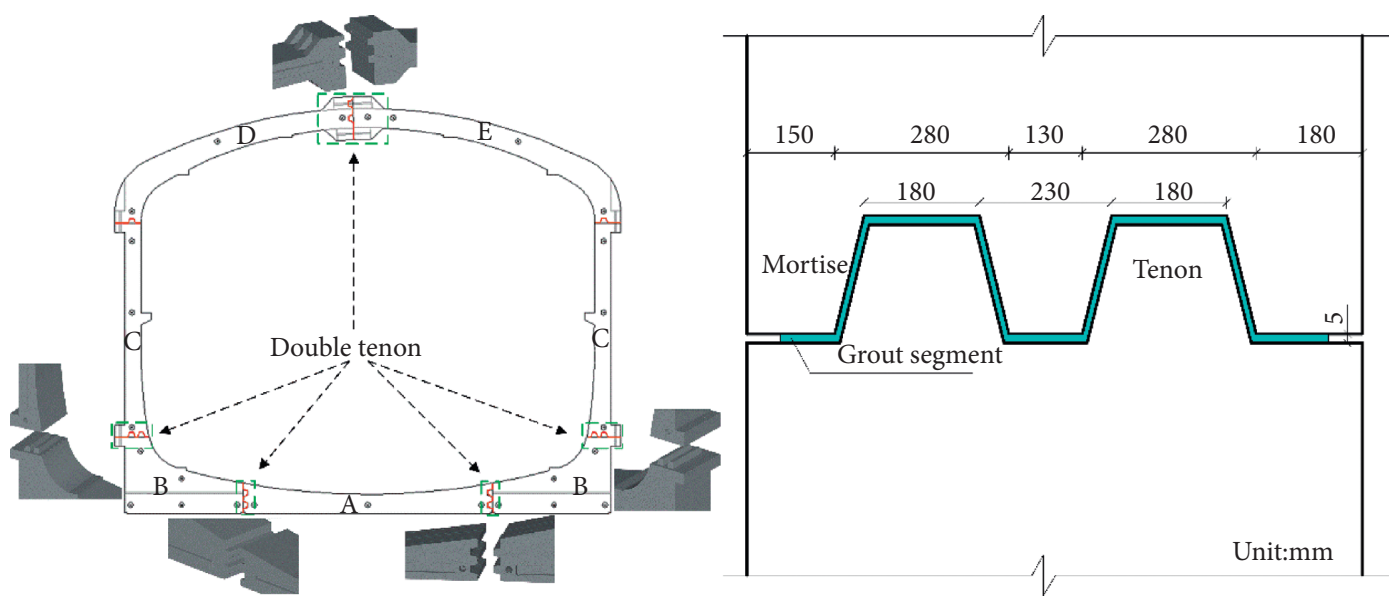

Figure 2: Arrangement and detail of double mortise-tenon joint.

TABle 1: Test cases.

\begin{tabular}{|c|c|c|}
\hline \multirow{2}{*}{$\begin{array}{l}\text { Test } \\
\text { cases }\end{array}$} & $\begin{array}{l}\text { Stable axial } \\
\text { load }\end{array}$ & $500 \mathrm{kN}, 1000 \mathrm{kN}, 1250 \mathrm{kN}$ \\
\hline & Three types & $\begin{array}{c}\text { Without auxiliary pretightening device, auxiliary pretightening device on tension side, auxiliary pretightening } \\
\text { device on compression side }\end{array}$ \\
\hline \multicolumn{2}{|c|}{ Test collection content } & $\begin{array}{l}\text { Concrete surface stress, reinforcement stress, record the whole process of joint and component crack } \\
\text { development, joint deformation, joint rotation }\end{array}$ \\
\hline
\end{tabular}

direction of crack III. At the final failure, a main through crack (crack III) appears at the tenon.

(c) The final failure of the joints without auxiliary pretightening device is cracking along the outer side of the tenon reinforcement protective layer, forming the main through crack III. The through-crack penetrates from tenon $\mathrm{A}$ to tenon $\mathrm{B}$ along the outer side of the protective layer. When the joint is finally damaged, cracks appear at the mortise position and connect with the tenon crack, and the outer side of the reinforcement protective layer on tensile side of the tenon shoulder $\left(B_{a}\right)$ is also cracked.

3.1.2. Crack Development of the Joint with Auxiliary Pretightening Device on Tension Side. For the specimen with auxiliary pretightening device on tension side, the crack development under different axial load conditions is summarized in Figure 7.

(a) Under the condition of small axial load $(500 \mathrm{kN})$, the first crack I appears at point $A_{a}$ and then appears crack II. At the same time, the crack III starts from the joint of grouting section and nongrouting section at the upper boss of $A_{a}$ near the shoulder of tension side, and it grows along the reinforced and concrete joint of tenon A.

(b) When the axial load is large $(1000 \mathrm{kN}$ and $1250 \mathrm{kN})$, the first crack I also appears at point $A_{a}$, and no crack II appears. When the crack I drives out of $B_{a}$ (the second arrow), crack III begins to develop.

(c) The small crack appears in the joint between the boss and the tenon when the crack III develops in the $B_{a}$ area. The small crack is short in length and develops slowly. A main through-crack appears at the tenon position at the final failure (crack III), which runs from the tenon of the tension side layer and along the outer side of the protective to the tenon of the compression side (from A to B). Cracks appear at the mortise position, which are connected with the tenon crack, and run to the shoulder (position $B_{a}$, between mortise $\mathrm{A}$ and mortise $\mathrm{B}$ ) at the outer side of the reinforcement protective layer on tension side.

3.1.3. Crack Development of the Joint with Auxiliary Pretightening Device on Compression Side. For the specimen with auxiliary pretightening device on compression side, the summary of crack development is shown in Figure 8.

(a) Under the condition of small axial load $(500 \mathrm{kN})$, the first crack I starts from the position of tenon foot on tension side (the intersection of $A_{a}$ and $A_{b}$ ) and develops along the reinforcement protective layer close to the joint surface $\left(A_{b}, A_{c}\right.$, and $\left.A_{d}\right)$.

(b) Under the condition of large axial load $(1000 \mathrm{kN}$ and $1250 \mathrm{kN}$ ), the first crack II develops along the direction of $B_{a}$ from the intersection point of $A_{a}$ and $A_{b}$. With the increase in bending moment, the development path of the first crack I appears under the condition of small axial load. Finally, when the crack passes through, crack III extends to the boundary between grouting section and nongrouting section on $A_{a}$.

(c) The joint of boss and tenon develops two cracks parallel to the steel bar from the boundary of 

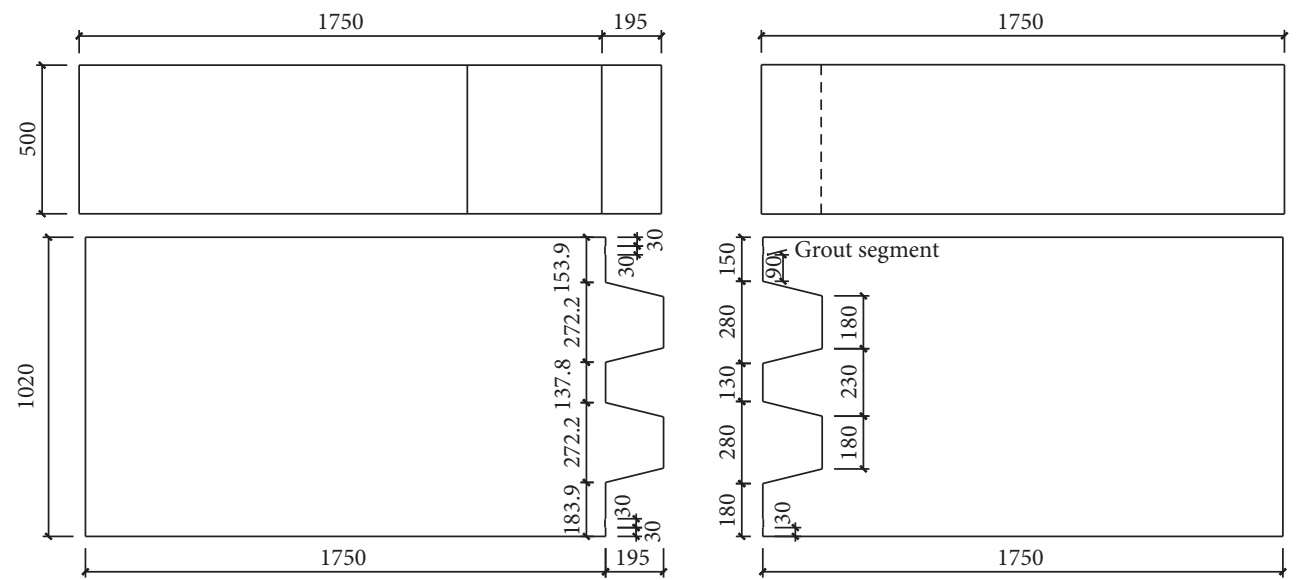

(a)
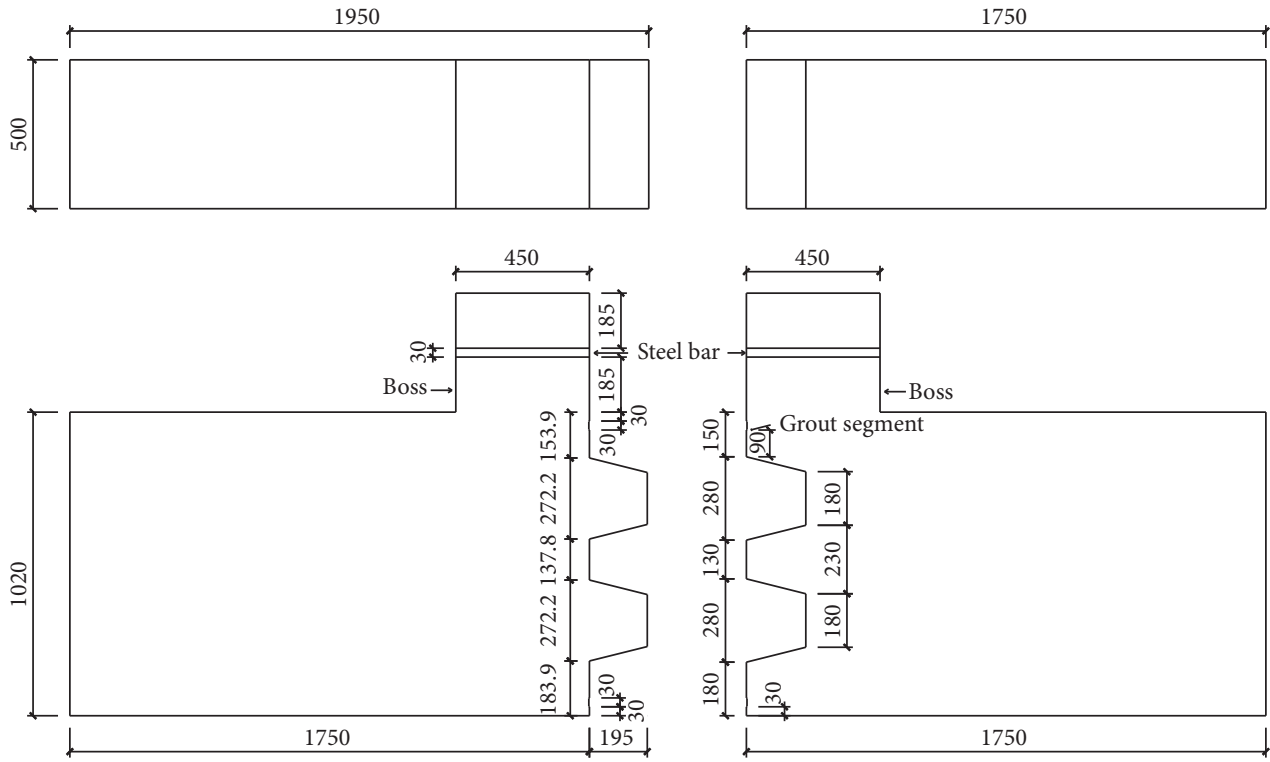

(b)

FIgURE 3: Specimens loading system layout: (a) without auxiliary pretightening device (unit: $\mathrm{mm}$ ); (b) with auxiliary pretightening device (unit: $\mathrm{mm}$ ).

grouting section and nongrouting section $\left(B_{e}\right)$ when the cracks develop into tenon $B$, which is close to the bearing limit moment.

(d) In the final failure, there is a main through-crack I at the tenon position, which runs through the tenon on tension side along the outer side of the protective layer from the tenon on tension side (from A to B). The crack appears at the mortise position, which is connected with the tenon crack, and cracks on the outer side of the reinforcement protective layer on tension side of the tenon shoulder $\left(B_{a}\right.$, located between mortise A and mortise B).

\subsection{Characteristic Curve of Bending Bearing Capacity.} The curve of bending moment-rotation $\mathrm{M}-\theta$ can directly reflect the bearing capacity of the joint, and combined with the law of crack development (mentioned in Section 3.1), a more intuitive characteristic curve of joint bending capacity can be obtained. The results show that the overall trend of M- $\theta$ curve of double-tenon joint is close to that of an auxiliary pretightening device, and the bearing characteristics are obvious. Taking the double-tenon joint without auxiliary pretightening device under an axial load of $1000 \mathrm{kN}$ as an example, the bending bearing characteristics of doubletenon joint are explained. Figure 9 shows the crack development of the joint surface during the whole loading process and its relationship with the load-bearing characteristic curve.

It can be seen that the bearing capacity of the joint has gone through four stages: linear stage I ( $0 \mathrm{kN} \mathrm{m} \sim 403 \mathrm{kN} \mathrm{m})$ : the slope is very small, and the proportion of the load to the total bearing capacity is large; the slope of the quasilinear stage II ( $403 \mathrm{kN} \mathrm{m} \sim 453 \mathrm{kN} \mathrm{m})$ is slightly smaller than that of the previous stage, and the proportion of the load to the total bearing capacity is small; the slope of the nonlinear 


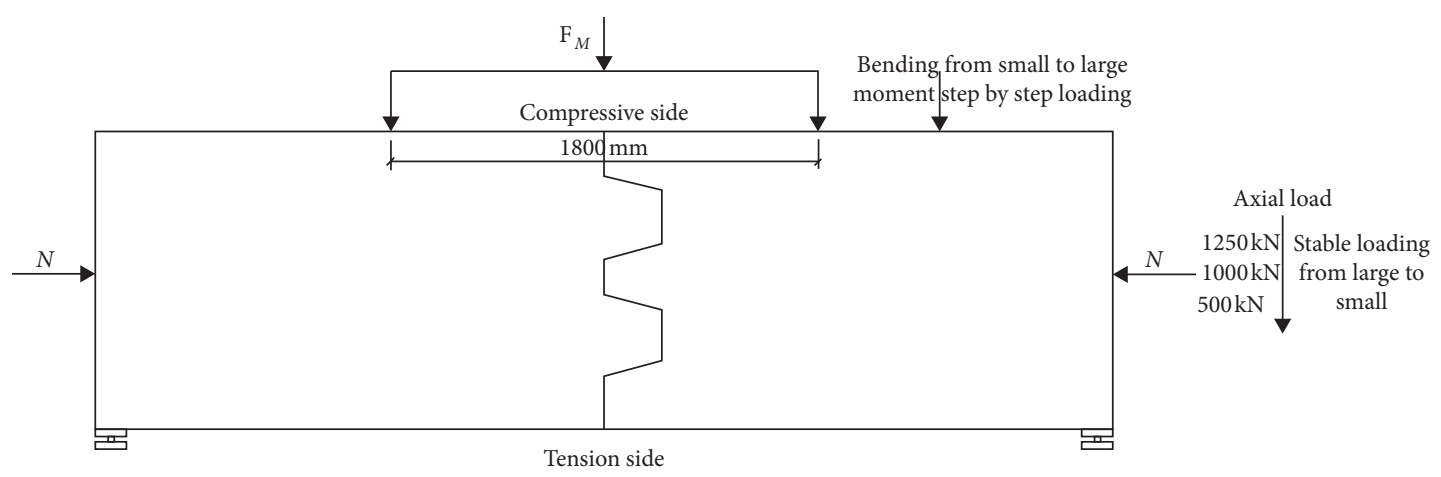

(a)

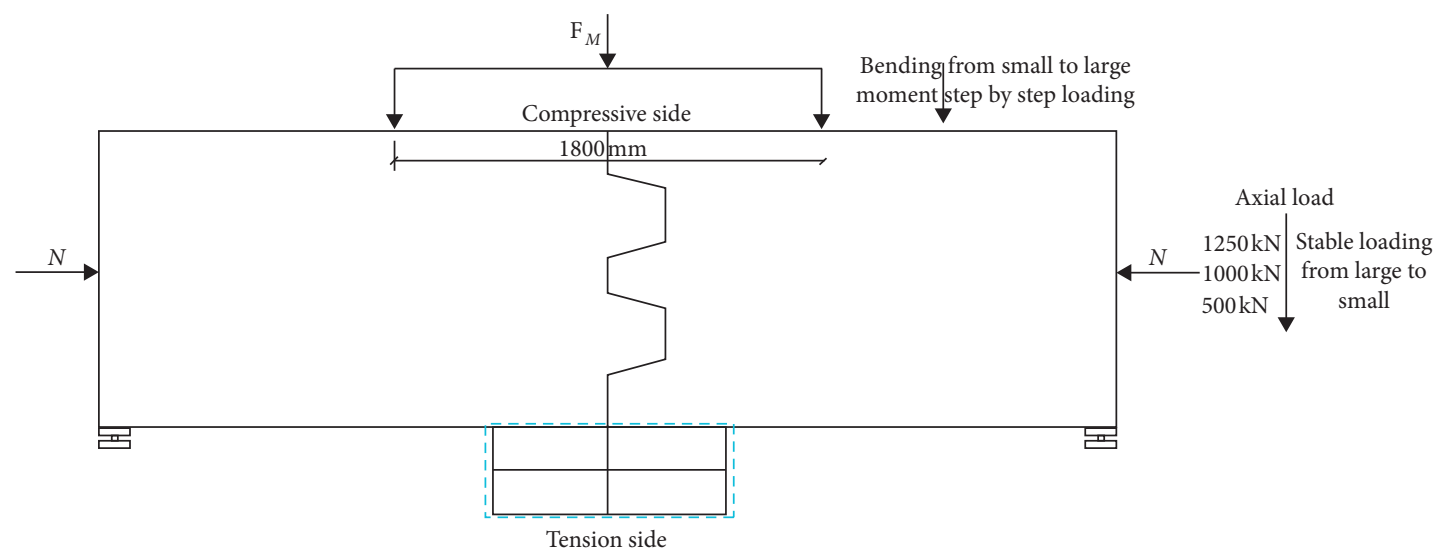

(b)

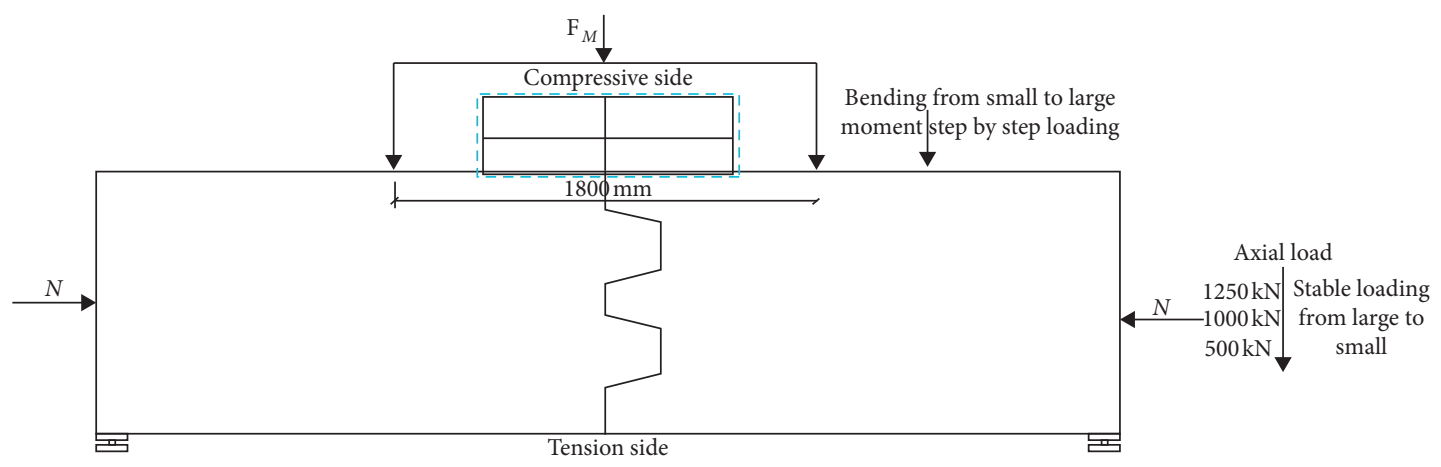

(c)

FIGURE 4: Layout for loading mode and sequence of specimens: (a) without auxiliary pretightening device; (b) auxiliary pretightening device on tension side; (c) auxiliary pretightening device on compression side.

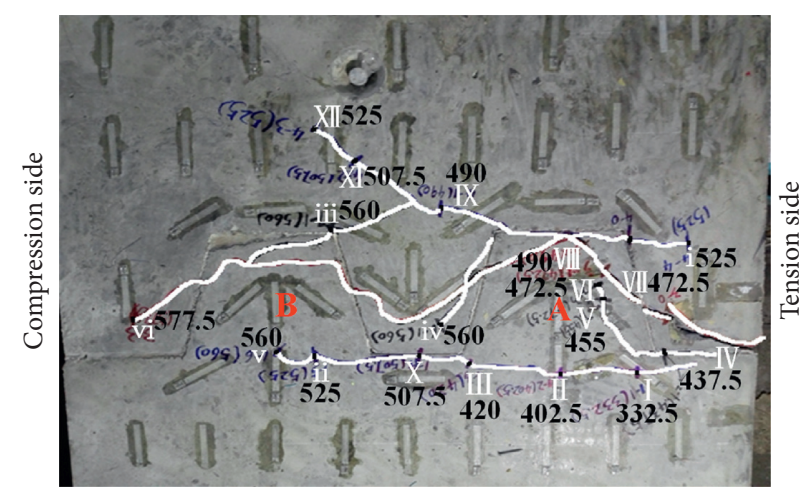

FIgURE 5: Crack development of double mortise-tenon joint without auxiliary pretightening device (axial load $1000 \mathrm{kN}$ ). 
TABLE 2: Crack development under increasing bending moment.

\begin{tabular}{lc}
\hline $\begin{array}{l}\text { Bending } \\
\text { moment }\end{array}$ & Crack development \\
\hline $332.5 \mathrm{kN} \cdot \mathrm{m}$ & $\begin{array}{c}\text { Crack I appears } \\
420 \mathrm{kN} \cdot \mathrm{m}\end{array}$ \\
$\begin{array}{l}455 \mathrm{kN} \cdot \mathrm{m} \\
490 \mathrm{kN} \cdot \mathrm{m}\end{array}$ & $\begin{array}{c}\text { Crack extends from II to III } \\
\text { Crack extends from IV to V }\end{array}$ \\
$525 \mathrm{kN} \cdot \mathrm{m}$ & Cracks XII (i and ii) appear, cracks IX (i) XI, and XII transfixion, cracks VII and VIII transfixion, tenon A transfixion \\
$577.5 \mathrm{kN} \cdot \mathrm{m}$ & Cracks VII and VIII connect the whole tenons and crack vi appears, crack iii and VII and VIII and vi connect, structural \\
crack transfixion & Crack extends from I to II \\
$402.5 \mathrm{kN} \cdot \mathrm{m}$ & Crack IV appears \\
$437.5 \mathrm{kN} \cdot \mathrm{m}$ & Through cracks i, IX, XI, and XII derive from cracks iii and iv, crack extends from ii to v, tiny cracks appear near the \\
$472.5 \mathrm{kN} \cdot \mathrm{m}$ & cracks IV, V, and VI, cracks between the two tenons A and B are connected \\
$507.5 \mathrm{kN} \cdot \mathrm{m}$ & $\begin{array}{c}\text { Crack extends from V to VI, crack VII appears } \\
560 \mathrm{kN} \cdot \mathrm{m}\end{array}$
\end{tabular}

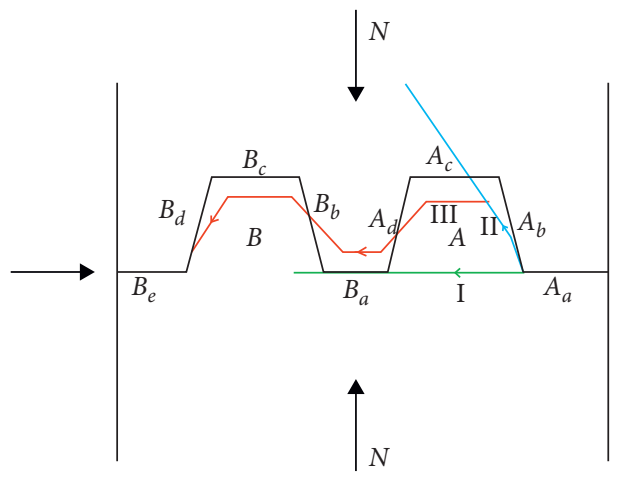

FIgURE 6: Crack development of double mortise-tenon joint without auxiliary pretightening device.

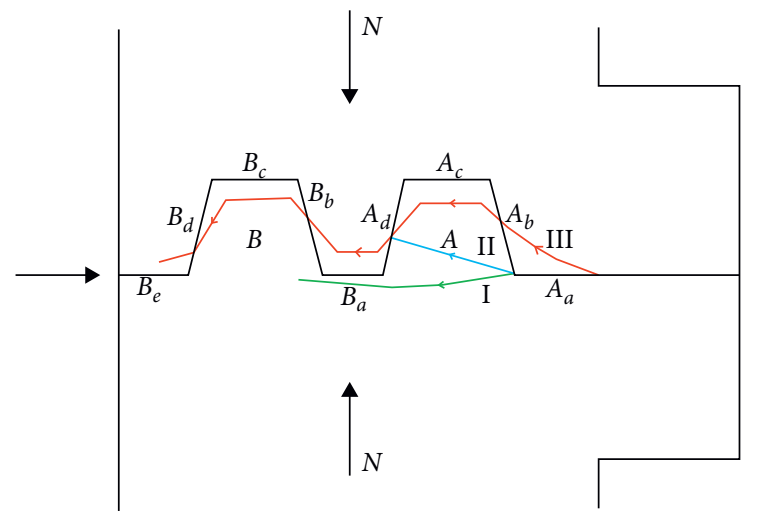

FIGURE 7: Crack development of double mortise-tenon joint with auxiliary pretightening device in tension side.

stage III ( $453 \mathrm{kN} \mathrm{m} \sim 539 \mathrm{kN} \mathrm{m})$ is obviously smaller than the first two stages, and it is the joint softening stage, which accounts for a larger proportion than stage II; at the end of bearing stage IV $(539 \mathrm{kN} \mathrm{m} \sim 578 \mathrm{k} \mathrm{kN} \cdot \mathrm{m})$, the slope tends to be horizontal, and the slight increase in bending moment leads to sharp increase in rotation angle, which accounts for a small proportion. In addition, it can be seen that the

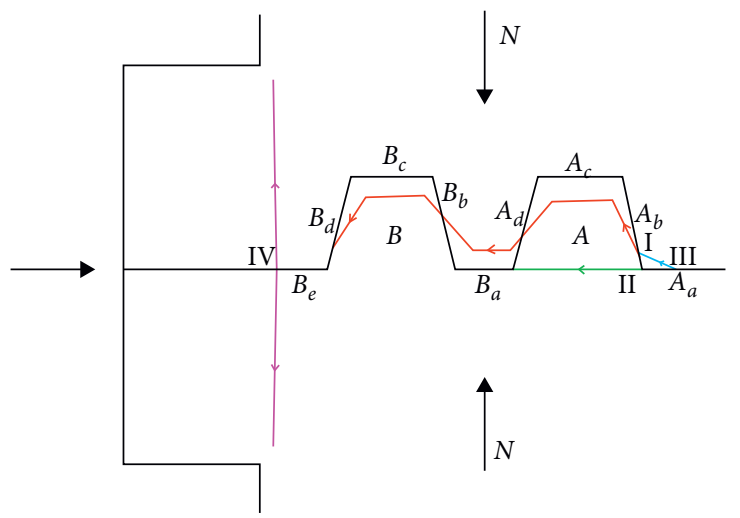

FIGURE 8: Crack development of double mortise-tenon joint with auxiliary pretightening device in compression side.

resistance moment $M_{R}$ almost coincides with the inflection point $\mathrm{b}$ (under the action of axial load, the moment $M_{R}$ is formed by the effective contact surface of the joint to resist the action of bending moment). When the joint is loaded beyond the resistance moment, the slope of the curve decreases obviously, and the bearing capacity obviously weakens. It also reflects that the bending resistance of the 


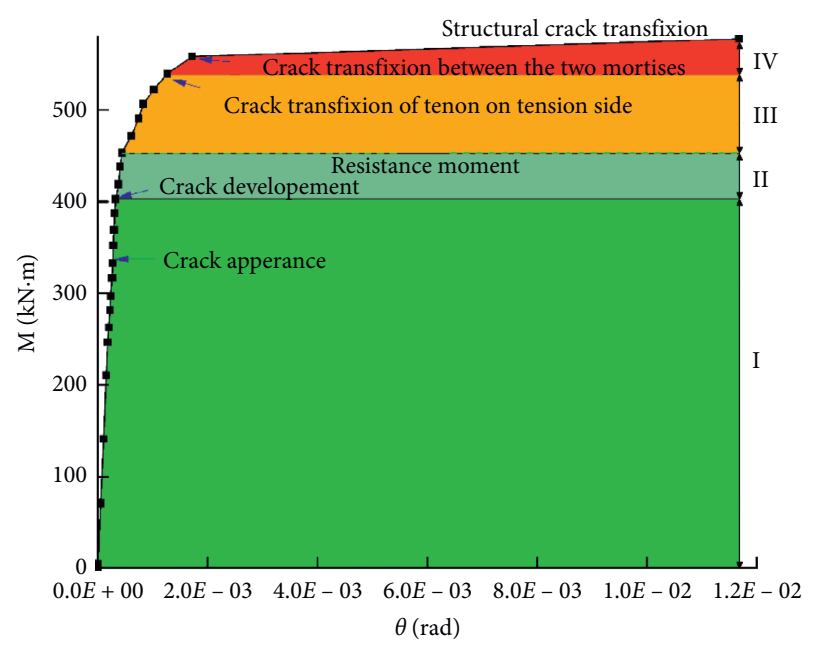

FIgURE 9: Relationship of crack development and bearing characteristic curve for double mortise-tenon joint.

tenon is not obvious due to the different properties of the two tenons (one pulls and one presses), and the ultimate failure state is the tenon pull-out.

From the perspective of crack development (combined with Figure 5), some concrete exceeds the limit state of tensile stress at the position of the foot of tenon A, and then, cracks appear for the first time at the end of stage I, so the linear stage ends. From stage II, the cracks begin to develop, but in the whole stage II, due to the effect of resistance moment, the development is relatively slow, and there are only small cracks in the inner part of tenon A. When the load exceeds the resistance moment, it enters stage III, the bending resistance of the tenon is weak, and the crack development increases. At the end of this stage, the cracks of tenon A are connected. Then, the curve goes into stage IV, and tenon $\mathrm{A}$ on tension side loses bearing capacity due to crack transfixion. At this time, the property of the tenon B on compression side changes from compression to tension, and bending performance of the tenon B becomes weak. Soon, cracks go through the mortise $A$ and mortise $B$, and then, the structural cracks go through and the joint loses the bearing capacity. The end of the bearing stage is relatively short.

\subsection{Analysis of Test Results Corresponding to Curve} Characteristics. The following results are combined with the concrete and reinforcement stress performance and the curve of the bending bearing characteristics of each bearing stage.

3.3.1. Performance of Concrete Surface Stress. It is found that the changes in concrete surface stress between the two tenons and the two tenon regions themselves are the most obvious, and the stress concentration phenomenon exists. The stress curve of tenon $\mathrm{A}$ on tension side changes most intensely, while the mechanical performance of tenon B on compression side is completely opposite to that of the tenon $\mathrm{A}$, and the change is obvious only after the cracks of tenon $\mathrm{A}$ pass through.
Also taking an axial load of $1000 \mathrm{kN}$ without auxiliary pretightening device condition as an example, the performance of concrete surface stress is explained in the following content. The layout of concrete strain gauges is shown in Figure 10, which shows the crack development when the joint is damaged. The measuring points outside the joint contour of the compression side and the tension side indicate the strain gauges attached to these two sides, i.e., the $500 \mathrm{~mm}$ wide surface shown in Figure 3. The development curve of concrete stress at representative measuring points is drawn in Figure 11, four stages of bearing are added, and the crack development stage is identified by dotted lines at the significant inflection points of the curve. Figure 11(a) represents the curve of measuring points at the position of the tenon on tension side, Figure 11(b) represents the curve of measuring points at the position of the tenon on compression side, and Figure 11(c) represents the curve of measuring points at the mortise between tenons $\mathrm{A}$ and $\mathrm{B}$ and the curve of measuring point on both sides of compression side and tension side. From these figures, we can see the following rules:

(a) From Figure 11(a): the first inflection point of tenon A appears around the resistance moment, and then, there is an obvious inflection point at the time of tenon penetration on tension side; the next inflection point occurs at the crack connection time between the two mortises at the end of the bearing period. The tensile stress state of \#73 and \#74 is obvious after the resistance moment, especially at \#74 which is closer to the tension side changes dramatically around the time of tenon penetration on tension side.

(b) From Figure 11(b): the properties of the tenon on compression side are completely different from those on tension side. The changes in the measuring points \#65 and \#67 in the first three stages and the measuring point \#66 in the first two stages are not obvious, and the later stage mainly shows the state of compressive stress.

When the load exceeds the resistance moment, the three measuring points have obvious inflection points at the time when the cracks of the two mortises pass through, and then, the compressive stress increases.

With the increase in the compressive stress, the increase in \#64 on the wall of the mortise on compression side increases continuously, and when the load exceeds the resistance moment, it reaches the limit state of compressive stress at the moment when the cracks between the two mortises pass through.

(c) Figure 11(c): the compressive stress of the measuring point \#58 located on compression side increases with loading, and the compressive stress becomes larger when the load exceeds the resistance moment. In stage IV, when the crack between the two mortises is connected, it increases rapidly to the limit state of compressive stress. 


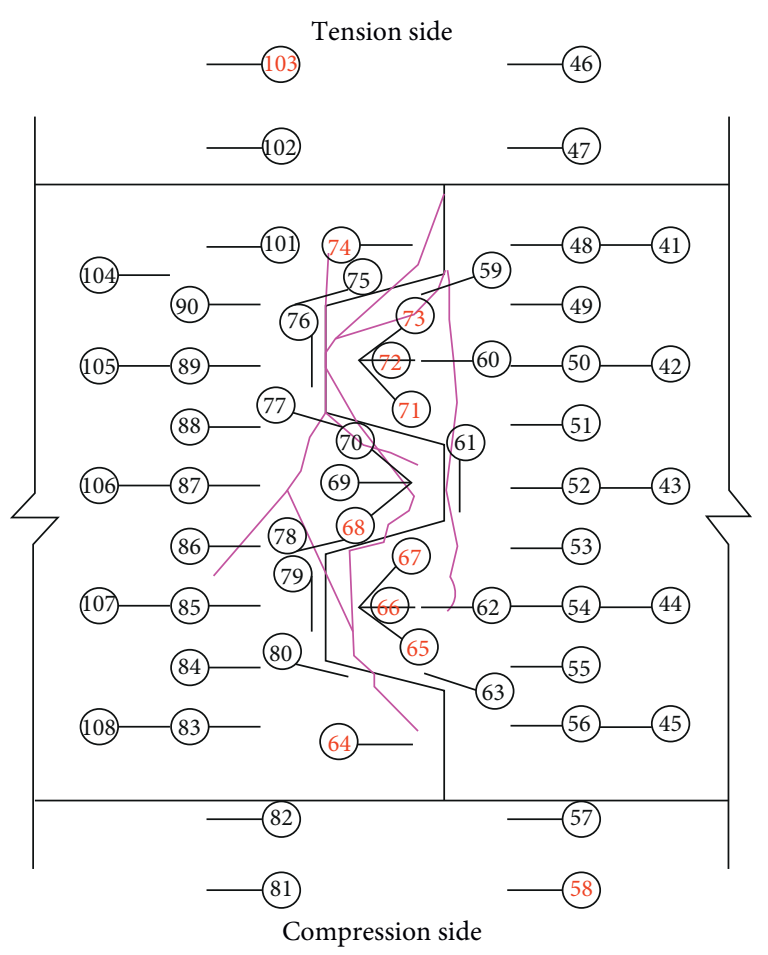

FIGURE 10: Strain gauge arrangement of concrete surface for an axial load of $1000 \mathrm{kN}$.

The tensile stress of the measuring point \#103 on tension side increases with loading and reaches the limit state of tensile stress in the middle of stage II.

The measuring point \#68 between the two mortises has little change in the first two stages. When the load exceeds the resistance moment, the compressive stress caused by the axial load decreases. At the later stage of stage III, tenon A reaches the minimum compressive stress state when the crack comes through the tenon $\mathrm{A}$, and then, the compressive stress increases; the inflexion point of increasing compressive stress appears when the cracks between the two mortises pass through. At this time, the crack passes through the strain gauge of \#68.

\subsubsection{Stress Performance of Reinforcement at Representative} Measuring Points. From the performance of reinforcement stress, it can also be observed that the closer to the tenon, the larger the stress of the measuring point, and the stress change in tenon and mortise is more severe than that in other places; there is a certain degree of stress concentration. Also taking an axial load of $1000 \mathrm{kN}$ without auxiliary pretightening device as an example, the stress change curve of the joint reinforcement is extracted in Figure 12. Figure (a) is the tenon area on tension side, and Figure (b) is the tenon area on compression side. From the figures, we can see the following rules:

(a) For the measuring point on the tenon $\mathrm{A}$ of the tension side, the reinforcement stress increases slowly with loading in the first two stages. The increasing speed is obvious when the load exceeds the resistance moment. At stage IV, the reinforcement stress increases obviously and reaches the peak value when the cracks between the two mortises pass through, which provides the main driving force for the joint's tensile strength.

(b) For the measuring points on the tenon $\mathrm{B}$ of the compression side, except the measuring points \#13 and $\# 15$ on the tenon are in the state of tensile stress at stage II when the load is close to the resistance moment; the rest of the measuring points change little in the first two stages and are in the state of compressive stress; when the load exceeds the resistance moment, the tensile stress increases slowly. The inflection point appears when the cracks between the two mortises are connected, and then, the tensile stress increases rapidly, but the change degree is less than that of the tenon on tension side.

(c) From the performance of reinforcement stress, the reinforcement stress changes little in the first two bearing stages, the bending resistance of the joint mainly depends on the resistance moment, and then, the tenon begins to play the bending role. Except for the measuring points on the tenon of the tension side, the overall reinforcement stress is not large. Due to the opposite effect of tension and compression of the two tenons, the bending effect of the tenons is not strong.

According to the inflexion point of stress on the tension and compression sides at the time the cracks between the two mortises pass through, combined with the performance of the crack and concrete stress, the failure mode of the joint is the tenon pull-out.

\subsection{Analysis of Joint Bearing Capacity at Different Stages.} The M- $\theta$ bending moment-rotation curves of different types of double-tenon joint under different working conditions are extracted. It is found that the bearing characteristic curve of double-tenon joint can be divided into four stages, which can be simplified into four polylines diagram, as shown in Figure 13. The bearing capacity space of different stages of double-tenon joint bearing characteristic curve and the relationship between each stage and crack development are also counted in Figure 13:

(a) The M- $\theta$ curve of double-tenon joint can be simplified as a three inflection points four polylines diagram. The load-bearing capacity is obviously divided into four stages. The proportion of each bearing stage in the whole bearing period is counted on the left side of the figure. Stage I is a linear segment, which accounts for the largest proportion, mainly depending on the resistance moment. Stage II is a quasilinear segment, the slope of stage II is slightly smaller than that of stage I, and its proportion is very small. The resistance moment of the section is also the main part in stage II. Stage III enters the nonlinear stage with joint softening. The slope of stage III is obviously lower than that of the 


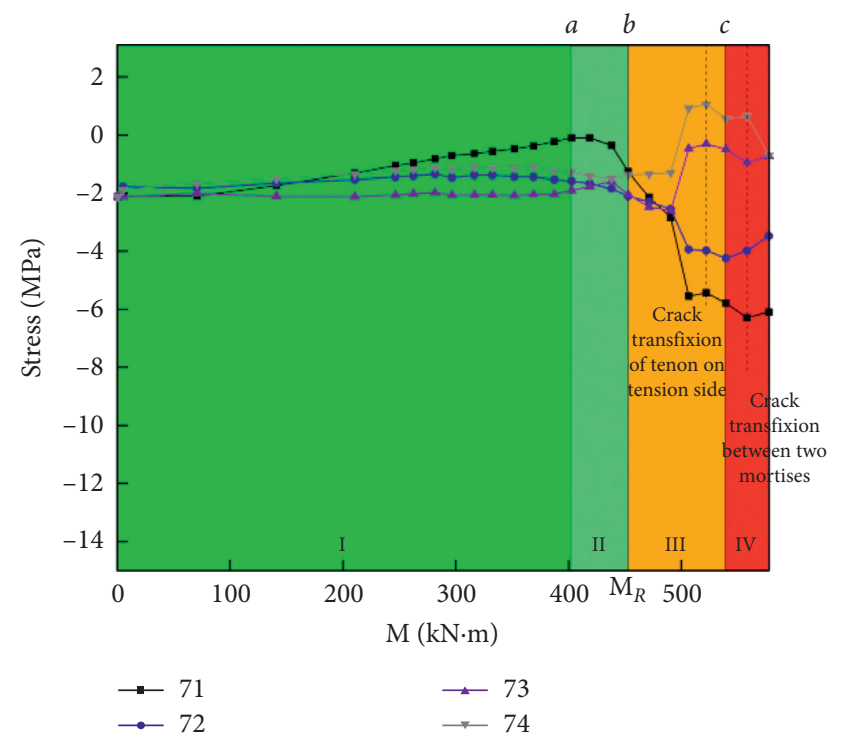

(a)

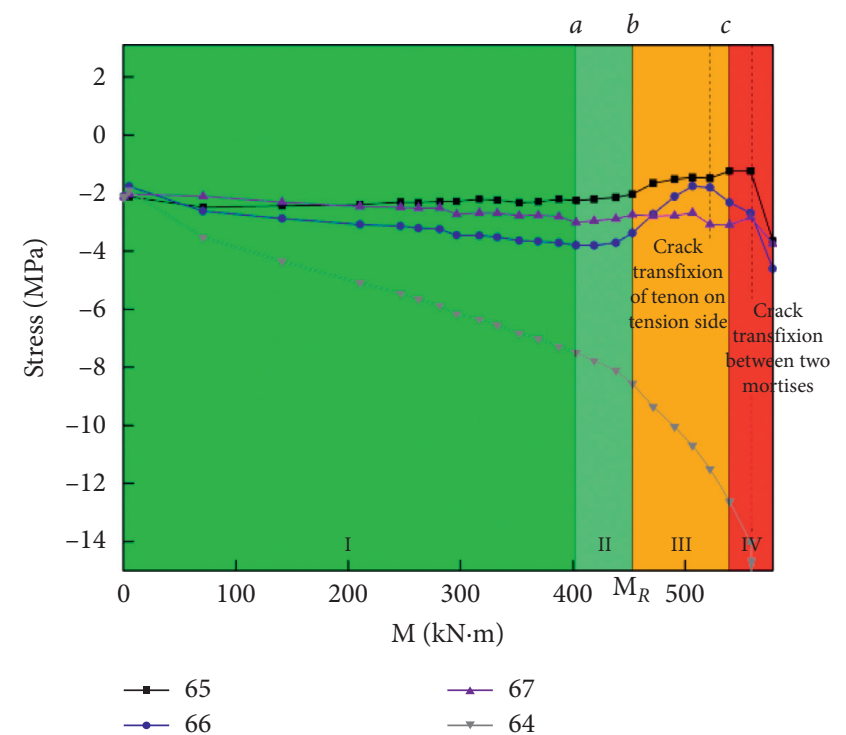

(b)

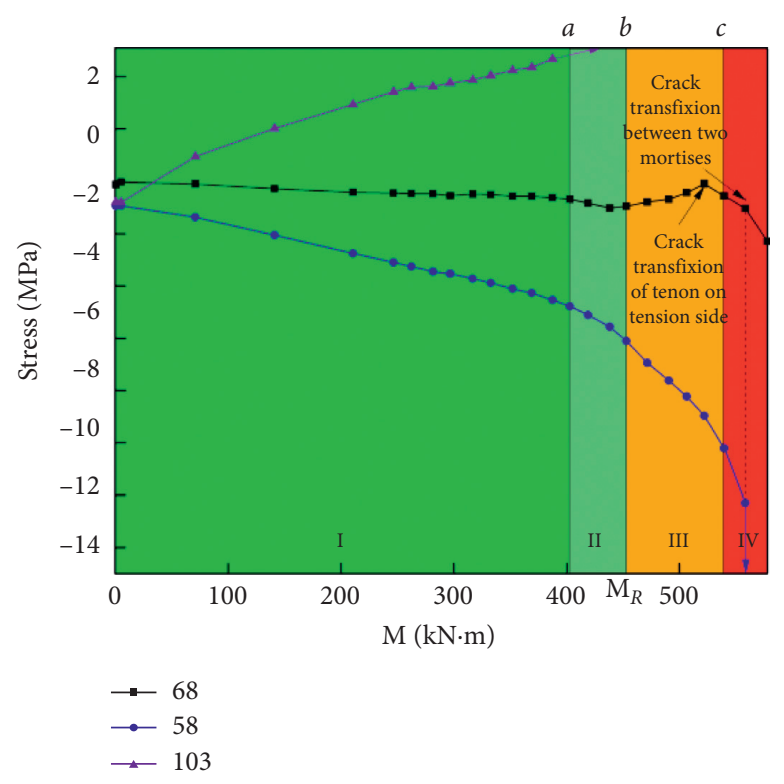

(c)

FIGURE 11: Change curve in stress with bending moment.

first two stages, and the proportion of this stage is almost twice as that of stage II, which mainly depends on the bending of tenon A on the tension side. The slope of stage IV decreases sharply, and the joint deformation intensifies and continues to weaken. Depending on the residual bending resistance of tenon $\mathrm{A}$ on tension side and the weak bending resistance of the region between mortise A and mortise $B$ which can also be regarded as the tenon on the mortise side $\left(B_{a}\right.$ position in Figure 6$)$, the joint carries out the final stage of loading.

(b) For the double-tenon joint, the resistance moment almost coincides with the boundary of stage II and stage III. When the load exceeds the resistance moment, the bearing capacity decreases. Depending on the bending resistance of tenon A on tension side and the engagement of three tenons (tenon $\mathrm{A}$ on tension side, tenon $\mathrm{B}$ on compression side, and the tenon between mortise $A$ and mortise $B$ on the mortise side), the joint has experienced a nonlinear stage III longer than stage II. In the later stage III, the crack of tenon A on tension side passes through, and the curve goes into stage IV with the bearing capacity decreasing rapidly. At this moment, the cracks between the two mortises are connected, and then, the bearing limit is quickly reached.

(c) According to statistics, the first two stages of all types of double-tenon joints (including those with 


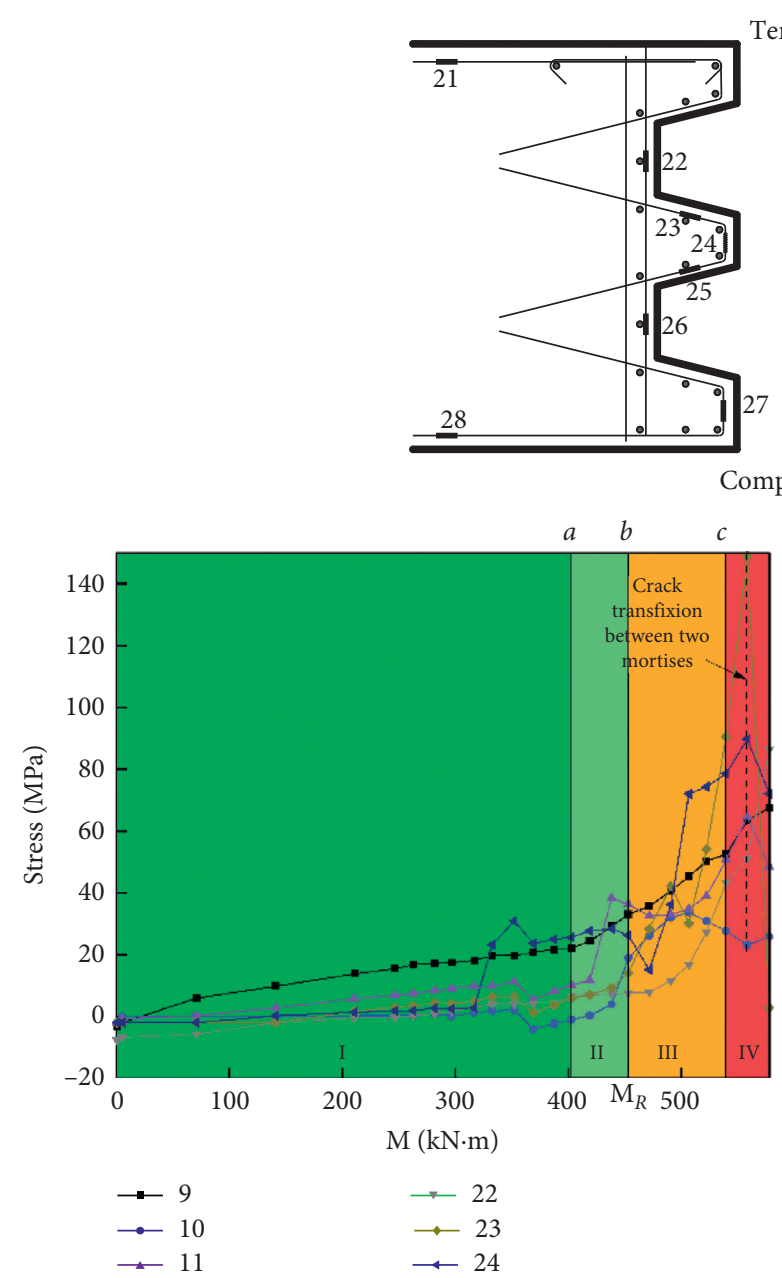

(a)

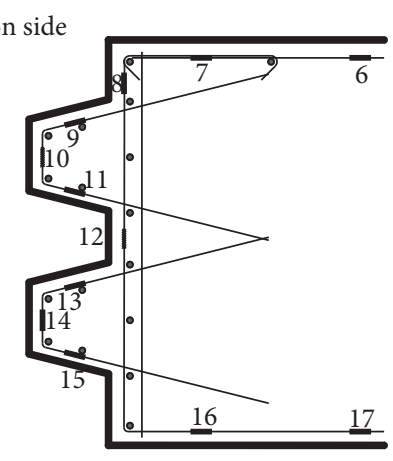

Compression side

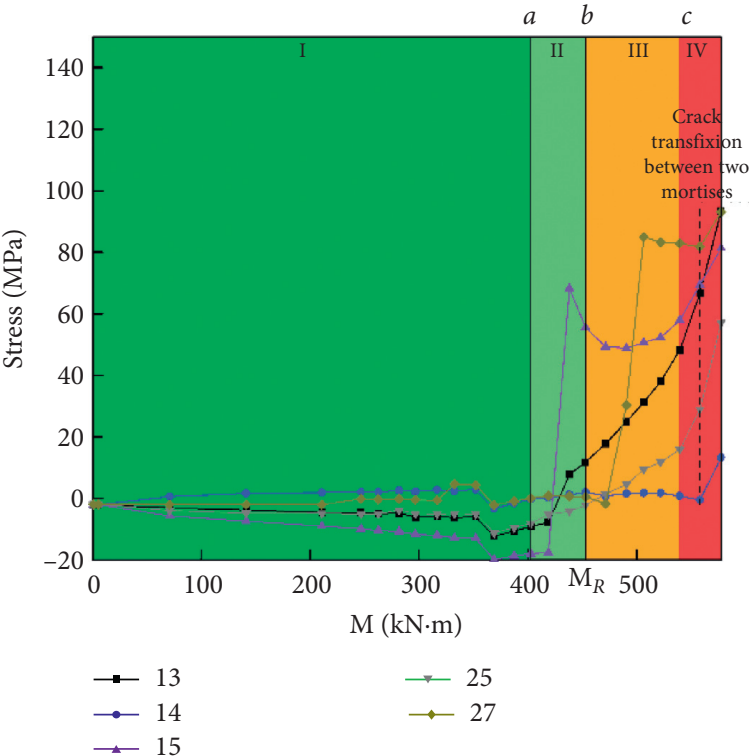

(b)

FIGURE 12: Change curve in reinforcement with bending moment (without auxiliary pretightening device).

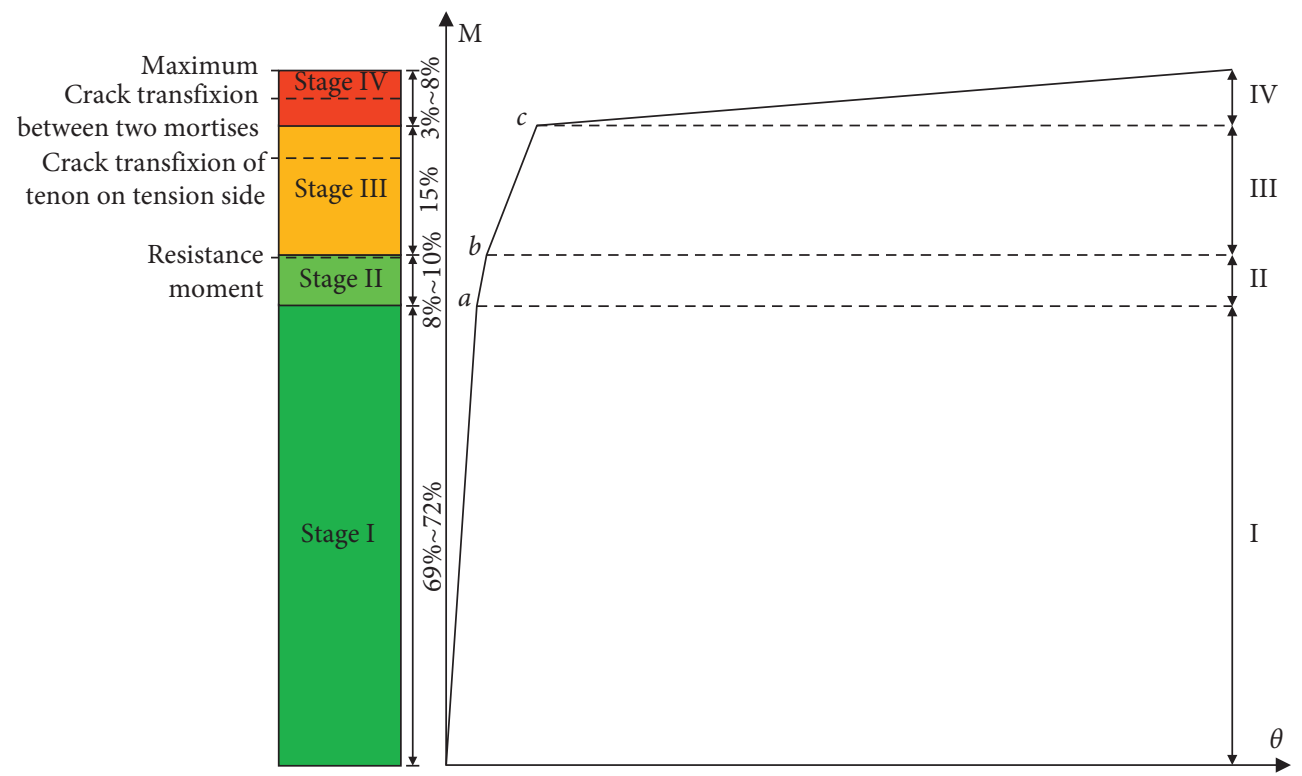

Figure 13: Bearing stage of bearing characteristic curve for grouted mortise-tenon joint. 
auxiliary pretightening tension devices) account for $77 \% \sim 82 \%$, and the first two stages mainly depend on section resistance moment, and the joint deformation is small, so it is recommended to consider the first two stages as the design and use stage.

\section{Bearing Capacity Analysis of Different Types of Double-Tenon Joint}

In order to judge the difference in bearing characteristics of different types of double-tenon joints more vividly, Figure 14 analyzes the stress change in reinforcement at the same position of different types of joints. Figure (a) shows the position of measuring point $\# 9$ of the tenon on tension side (see Figure 12 reinforcement stress arrangement), and Figure (b) shows stress change in pretightening steel bar. From the figure, the following is observed:

(a) It can be seen from the stress change in measuring point $\# 9$ on the tenon $A$ of the tension side that the curve of the joint without auxiliary pretightening device is close to the joint with auxiliary pretightening device on tension side, and the tensile stress increases with the increase in bending moment. When the load exceeds the resistance moment, the curve increases faster, and the auxiliary pretightening device increases the bearing capacity, and the curve is longer than joint without auxiliary pretightening device. However, the curve of the joint with auxiliary pretightening device on compression side does not start to play a tensile role until the inflection point $c$. The reason is that after the auxiliary pretightening device is compressed on the compression surface, the section resistance length actually increases, and the actual resistance moment is greater than the other two types. Therefore, at the end of the bearing period, tensile stress of the reinforcement at measuring point \#9 which is close to the tensile side increases, because at the end of the bearing period, the increase and the slope of the curve are very large.

(b) From the comparison of the stress of the pretightening steel bar on tension side and the compression side, the pretightening steel bar on tension side is fully developed and reaches the yield strength after the cracks of the two tenons are connected. When the auxiliary pretightening device is located on the compression side, the tensile performance of the pretightening steel bar is not fully exerted, and it shows the compressive stress state in the later stage.

Next, the bending moment of typical crack development stages of various types of double-tenon joints under different axial loads is shown in Figure 15, and the resistance moment of various types of double-tenon joints is also counted in the figure. From the figure, the following could be inferred:

(a) The bending moment of double-tenon joint increases with the increase in axial load. (b) The bending moment of the joint with auxiliary pretightening device is significantly larger than the joint without auxiliary pretightening device in typical stage. For example, compared with the joint without auxiliary pretightening device, under the action of an axial load of $500 \mathrm{kN}$, the bending moment of crack appearance is increased by $6.67 \%$, the bending moment of crack transfixion of tenon $\mathrm{A}$ on tension side is increased by $40.91 \%$, the bending moment of crack transfixion between mortise A and mortise B is increased by $39.13 \%$, and the ultimate bearing moment is increased by $37.5 \%$. Under the action of an axial load of $1000 \mathrm{kN}$, the bending moment increases by $10.53 \%$ when cracks appear, the bending moment increases by $13.33 \%$ when the crack passes through tenon $\mathrm{A}$ on tension side, the through bending moment of cracks between mortise $\mathrm{A}$ and mortise $\mathrm{B}$ increases, and the ultimate bearing moment increases by $39.39 \%$. Under the action of an axial load of $1250 \mathrm{kN}$, the bending moment increases by $4.84 \%$ when cracks appear, the bending moment increases by $25 \%$ when the crack passes through tenon $\mathrm{A}$ on tension side, the bending moment of crack transfixion between mortise A and mortise $B$ increases by $21.05 \%$, and the ultimate bearing moment increases by $20.51 \%$. It can be seen that the setting of auxiliary pretightening device plays a more obvious role in delaying the appearance of cracks and improving the ultimate bearing capacity under the action of small axial load.

(c) Compared with the auxiliary pretightening device on tension side, the bending moment of the auxiliary pretightening device on compression side is smaller, which is $6.8 \%$ less at $1250 \mathrm{kN}$ and $6.9 \%$ at $1000 \mathrm{kN}$, and the amplitude reaches $32 \%$ under small axial load $(500 \mathrm{kN})$. The bending moments of the auxiliary pretightening device on compression side are 15\% and $14 \%$ larger at the beginning of the crack under the condition of large axial load $(1000 \mathrm{kN}$ and $1250 \mathrm{kN}$ ).

(d) When the load exceeds the resistance moment, the joint cracks develop, and then, the cracks of tenon A on tension side pass through. At this time, there is no crack in the region of mortise $\mathrm{B}$ on compression side and the tenon between tenon A and tenon B. It can be seen that when the load is greater than the resistance moment, the tenon A on tension side first plays an occlusive role, which mainly bears the tensile force, and failure mode of tenon A belongs to the tensile failure during which the crack penetrates to failure. However, when the cracks of tenon A on tension side are penetrated, the tenon B on compression side starts occlusion. Although the main bearing pressure is compression stress, the tenon A on tension side loses the main bearing capacity after the crack is penetrated, and the crack propagation tension is transmitted. Finally, the tenon $\mathrm{B}$ on compression side does not reach the 


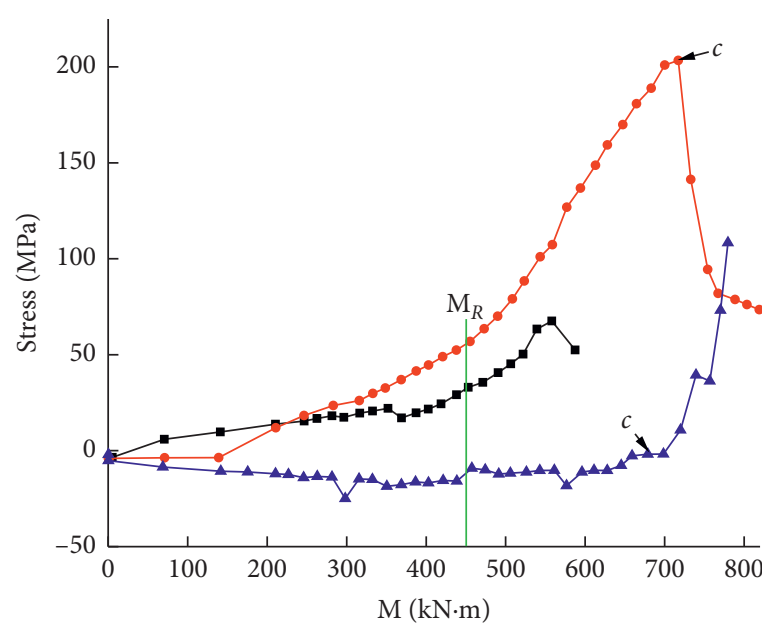

$\longrightarrow$ Without auxiliary pretightening device

$\rightarrow$ Auxiliary pretightening device on tension side

$\neg$ Auxiliary pretightening device on compression side

(a)

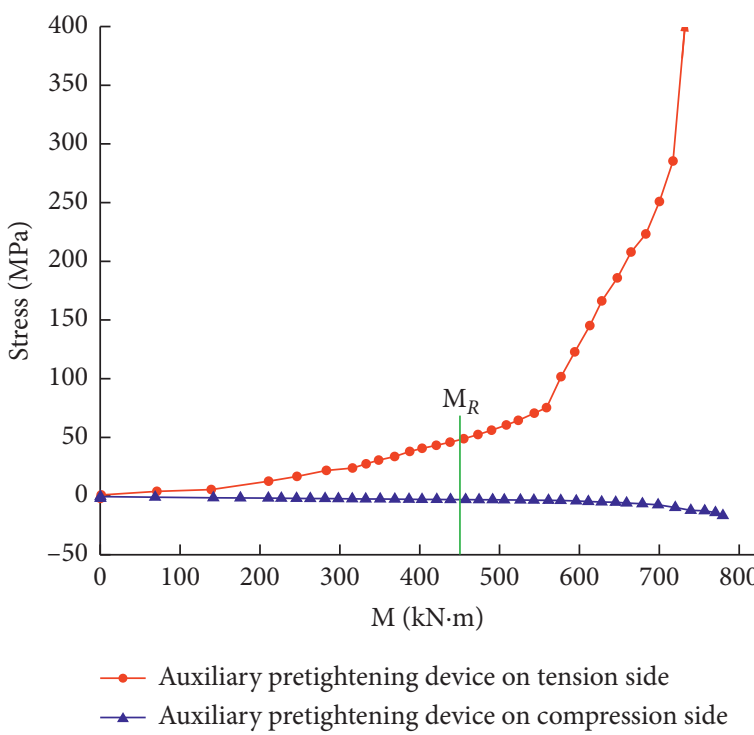

(b)

FIGURE 14: Comparison of rebar stress for different types of double mortise-tenon joints.
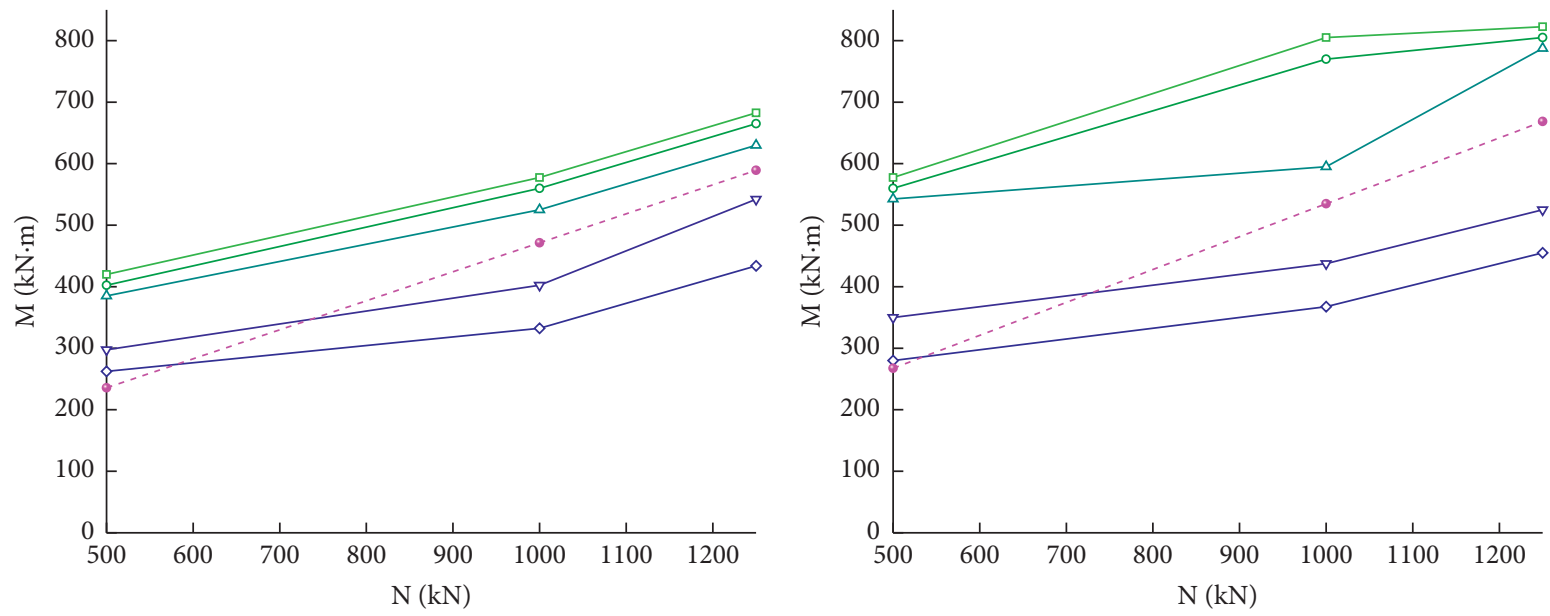

\footnotetext{
- - Structural crack transfixion

- - Crack transfixion between the two mortises

$\rightarrow-$ Crack transfixion of tenon on tension side

$\rightarrow$ Crack development

$\rightarrow$ Crack appearance

- - Resistance moment
}

$\rightarrow$ Structural crack transfixion

- Crack transfixion between the two mortises

$\triangle-$ Crack transfixion of tenon on tension side

$\rightarrow$ Crack development

$\rightarrow$ Crack appearance

- - Resistance moment

Figure 15: Continued. 


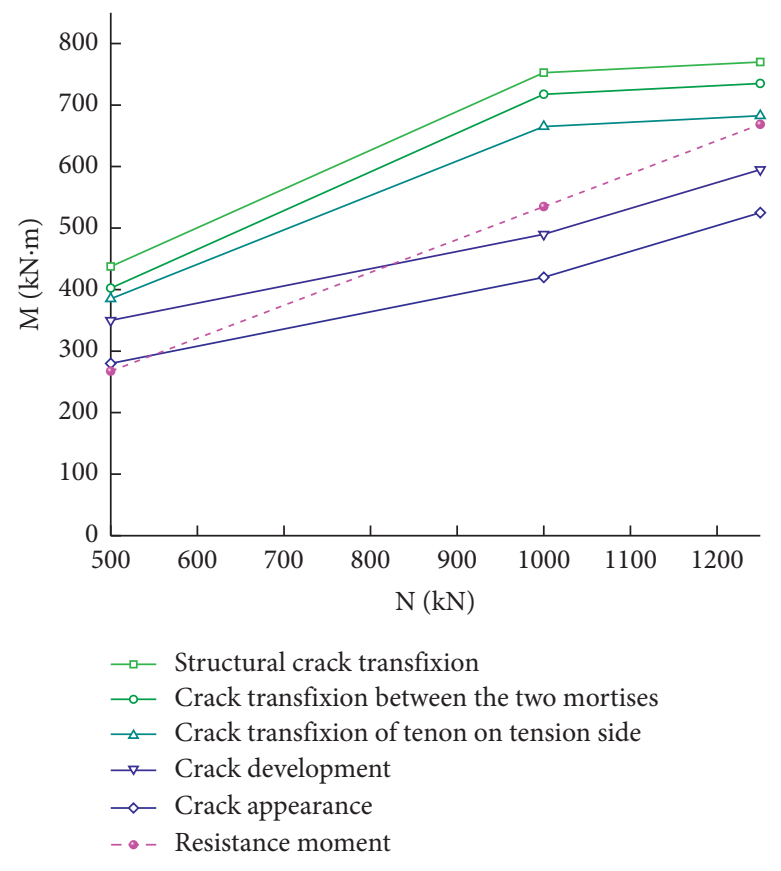

(c)

FIGURE 15: Key bending moments of different double mortise-tenon joints under various loads: (a) without auxiliary pretightening device; (b) auxiliary pretightening device on tension side; (c) auxiliary pretightening device on compression side.

compressive stress limit, which is affected by the crack development caused by the tensile force from the tenon $\mathrm{A}$ on tension side to the mortise between tenon $\mathrm{A}$ and tenon $\mathrm{B}$. The failure mode of tenon $\mathrm{B}$ also belongs to the tensile failure. It can be seen from the figure that the above phenomenon occurs when the axial load is greater than or equal to $800 \mathrm{kN}$.

When the axial load is less than or equal to $800 \mathrm{kN}$, especially under the condition of $500 \mathrm{kN}$, the crack will appear only after the load exceeds the resistance moment. The reason is that the contribution of the axial load component under the action of large axial load makes the distinction of the pulling and pressing properties of the two tenons more obvious, while under the action of small axial load, the two tenons play the occlusive role of the key teeth with only little help of resistance moment. The influence of the different properties of the tenons with one pulling and one pressing is not obvious under the action of the small axial force. That is to say, under the condition of small axial load, when the load exceeds the resistance moment, the tenon can play some bending functions to resist the force, but under the condition of large axial load, when the load exceeds the resistance moment, the bending effect of the joint with one pulling tenon and one pressing tenon is weakened. The tenon A on tension side plays the main role, and the bending effect of tenon $\mathrm{A}$ on tension side is greater than that of tenon $\mathrm{B}$ on compression side. The ultimate failure mode is that the two tenons are pulled out successively.

\section{Conclusion}

In this paper, the $1: 1$ prototype load-bearing performance and destructive test of the double-tenon joint with a different stiffness in various types and working conditions are carried out. Through the analysis of the results and the in-depth study on its failure mode and bearing performance, the following conclusions are obtained:

(a) When the load exceeds the resistance moment, the tenon on tension side plays a main bearing role. Finally, the failure mode is that the two tenons are damaged one after another. The main crack develops along the tenon outline on tensile side and penetrates into the tenon on compression side.

(b) The load-bearing characteristic curve of doubletenon joint can be simplified as three inflection points and four polylines diagram. The bearing capacity is divided into four stages: stage I is linear, the bearing capacity mainly depends on the section resistance moment; stage II is quasilinear, and the bearing capacity is also dominated by section resistance moment; stage III is nonlinear, which mainly depends on the bending resistance of the tenon on tension side; stage IV is nonlinear, the joint has been weakened, and the tenon remains the residual bending resistance.

(c) For the same type of double-tenon joint, under the same loading mode, the bending moment of each key stage increases with the increase in axial load. 
The greater the axial load is, the stronger the bending resistance of the joint is.

(d) Under the same axial load condition, the bending moment of the critical stage of the joint with auxiliary pretightening device (pretightening steel bar + boss) is significantly larger than the joint without auxiliary pretightening device. The auxiliary pretightening device is helpful to delay the occurrence of cracks and improve the bearing capacity, especially when the axial load is small.

(e) It is more effective to place the pretightening steel bar on tension side than on compression side.

\section{Data Availability}

The data used to support the findings of this study are available from the corresponding author upon request.

\section{Conflicts of Interest}

The authors declare that there are no conflicts of interest.

\section{Authors' Contributions}

Xiuren Yang supervised the project and developed the concept and methodologies with Meiqun Huang. Fang Lin performed the experimental and theoretical studies.

\section{Acknowledgments}

This research was funded by the National Key S\&T Special Projects (Grant no. 2017YFB1201104).

\section{References}

[1] L. Rozsa, "Precast concrete segment lining of the Budapest Metro," Tunnels \& Tunnelling International, vol. 11, no. 10, 1979.

[2] K. Beilasov, Q. H. Qian, and C. Z. Qi, The Essence of the Construction of Russian Underground Railway, China Railway Press, Beijing, China, 2012.

[3] J. H. Liu and X. Y. Hou, "The History of Shield Tunneling,", China Railway Press, Beijing, China, 1991.

[4] H. Backmann and A. Steinle, Precast Concrete Structures, Ernst \& Sohn, Berlin Germany, 2011.

[5] J. Bi, X. P. Zhou, and Q. H. Qian, "The 3D numerical simulation for the propagation process of multiple pre-existing flaws in rock-like materials subjected to biaxial compressive loads," Rock Mechanics and Rock Engineering, vol. 49, no. 5, pp. 1611-1627, 2016.

[6] Y.-H. Huang, S.-Q. Yang, P. G. Ranjith, and J. Zhao, "Strength failure behavior and crack evolution mechanism of granite containing pre-existing non-coplanar holes: experimental study and particle flow modeling," Computers and Geotechnics, vol. 88, pp. 182-198, 2017.

[7] J. Bi, P. Liu, and F. Gan, "Effects of the cooling treatment on the dynamic behavior of ordinary concrete exposed to high temperatures," Construction and Building Materials, vol. 248, Article ID 118688, 2020.

[8] Q. H. Qian and X. P. Zhou, "Failure behaviors and rock deformation during excavation of underground cavern group for Jinping I hydropower station," Rock Mechanics and Rock Engineering, vol. 51, no. 8, pp. 2639-2651, 2018.

[9] Q. H. Qian, X. P. Zhou, H. Q. Yang, Y. X. Zhang, and X. H. Li, "Zonal disintegration of surrounding rock mass around the diversion tunnels in Jinping II Hydropower Station, Southwestern China," Theoretical and Applied Fracture Mechanics, vol. 51, no. 2, pp. 129-138, 2009.

[10] T. Liu, J. Lu, D. Wang, and H. Liu, "Experimental investigation of the mechanical behaviour of wall-beam-strut joints for prefabricated underground construction," International Journal of Concrete Structures and Materials, vol. 15, no. 1, pp. 1-19, 2021.

[11] X. R. Yang, M. Q. Huang, and F. Lin, "Research strategies on new prefabricated technology for underground metro stations," Urban Rail Transit, vol. 5, pp. 145-154, 2019.

[12] X. R. Yang and F. Lin, "Prefabrication technology for underground metro station structure," Tunnelling and Underground Space Technology, vol. 108, Article ID 103717, 2021.

[13] X. R. Yang, Z. H. Shi, and Z. F. Lin, "Influence of geometrical parameters on performance of grouted mortise and tenon joints for application in prefabricated underground structures," Advances in Civil Engineering, vol. 2019, Article ID 3747982, , 2019.

[14] X. R. Yang, Z. H. Shi, and Z. F. Lin, "Research on shear capacity and checking method of MT. G-joint for application in prefabricated underground structures," Advances in Materials Science and Engineering, vol. 2019, Article ID 4065301, 2019.

[15] S. Teachavorasinskun and T. Chub-Uppakarn, "Influence of segmental joints on tunnel lining," Tunneling and Underground Space Technology, vol. 25, no. 4, pp. 490-494, 2010.

[16] D. A. Steinhardt and K. Manley, "Adoption of prefabricated housing-the role of country context," Sustainable Cities and Society, vol. 22, pp. 126-135, 2016.

[17] B. Tvede-Jensen, M. Faurschou, and T. Kasper, "A modelling approach for joint rotations of segmental concrete tunnel linings," Tunnelling and Underground Space Technology, vol. 67, pp. 61-67, 2017.

[18] X. R. Yang, M. Q. Huang, and F. Lin, "Experimental method of grouted mortise-tenon joint for prefabricated metro station structure," Urban Rail Transit, vol. 32, no. 5, pp. 83-90, 2019. 